\title{
Variabilidade espacial das propriedades dendrométricas do eucalipto e atributos químicos de um Neossolo Quartzarênico
}

\author{
Elizeu de Souza Lima ${ }^{1}$, Rafael Montanari², Lenon Henrique Lovera², Marcelo Carvalho \\ Minhoto Teixeira Filho², Antonio Paz González ${ }^{3}$
}

\begin{abstract}
${ }^{1}$ Universidade Estadual de Campinas - UNICAMP, Campinas, São Paulo, Brasil. E-mail: elizeu.florestal@gmail.com
2 Universidade Estadual Paulista "Júlio de Mesquita Filho" - UNESP, Campus de Ilha Solteira, Ilha Solteira, São Paulo, Brasil. Email: montanari@agr.feis.unesp.br, lhlovera@gmail.com, mcmteixeirafilho@agr.feis.unesp.br
\end{abstract}

${ }^{3}$ Universidade da Coruña - UDC, Facultad de Ciencias, Campus de A Zapateira, Coruña, Espanha. E-mail: tucho@udc.es

Recebido: 28/07/2016; Aceito: 31/10/2016

\section{RESUMO}

A geração de grandes quantidades de resíduos sólidos e efluentes pelas indústrias de celulose e papel tem se constituído em preocupação ambiental. Este trabalho objetivou analisar as correlações lineares do desenvolvimento individual das árvores de Eucalyptus urograndis, em função dos atributos químicos de um Neossolo Quartzarênico, com vistas a evidenciar zonas específicas de manejo intimamente associadas ao desenvolvimento do eucalipto no intuito de utilizar a lama de cal da extração da celulose na forma de fertilizantes de maneira sustentável ao ambiente. Foi instalada uma malha experimental de aproximadamente 2 ha, contendo 50 pontos amostrais em um Neossolo Quartzarênico e posteriormente coletados atributos de planta e solos para a determinação dos atributos químicos nas camadas de 0-0,20 m e 0,20-0,40 m município de Três Lagoas (MS). Os resultados foram analisados por meio da estatística clássica e geoestatística. A dependência espacial varia conforme o atributo químico avaliado e a profundidade de coleta. Além da variabilidade vertical, há também variabilidade horizontal entre as profundidades, visto que para um mesmo nutriente o alcance foi diferente entre as camadas amostradas.

Palavras-chave: Resíduos celulósicos, sustentabilidade florestal, oxyfertil, geoestatística.

\section{Spatial variability of eucalyptus dendrometric properties and chemical attributes of a Quartzarenic Neosol}

\begin{abstract}
The generation of large quantities of solid waste and effluents from pulp and paper industry has made environmental worry. This study aimed to analyze the linear correlations of individual development of Eucalyptus urograndis trees depending on the chemical properties of a Quartzarenic Neosol, in order to highlight specific areas of closely managing associated with the development of eucalyptus in order to use the lime sludge extraction cellulose in the form of sustainably fertilizer to the environment. An experimental grid approximately $2,0 \mathrm{~h}$ was installed containing 50 sampling points in a Quartzarenic Neosol and then collected plant attributes and soil for the determination of chemical parameters in the layers of $0-0.20$ and $0.20-0.40 \mathrm{~m}$ municipality Três Lagoas (MS). The results were analyzed by classical statistical and geostatistical. The spatial dependence varies according to the assessed chemical attributes and depth collection. In the vertical variability, there are also horizontal variations among the depths, since for the same nutrient scope was different between the sampled layers.
\end{abstract}

Key words: cellulosic waste forest sustainability, oxyfertil, geostatistics. 


\section{Introdução}

O cultivo de Eucalyptus spp. no Brasil tem aumentado devido ao rápido crescimento, diversificação no uso da madeira e pela facilidade de adaptação às diferentes condições edafoclimáticas. Tal fato faz com que a produtividade das plantações comerciais de eucalipto no Brasil seja bastante variável. Segundo o Serviço Florestal Brasileiro (2016), o Brasil obtém hoje as melhores tecnologias na silvicultura do eucalipto, atingindo cerca de $60 \mathrm{~m}^{3} \mathrm{ha}^{-1}$ de produtividade média em rotações de sete anos.

O aumento na produção madeireira levou o setor de papel e celulose brasileiro a destaque na área florestal em âmbito mundial como o quarto maior produtor de celulose, o nono maior produtor de papel, além de ser o $13^{\circ}$ maior mercado de consumidores per capita de papel, contando com um total de 220 empresas de celulose e papel ativas em 540 municípios, localizados em 18 estados (TOLEDO et al., 2015).

Produzindo papel e celulose, as indústrias do setor florestal têm gerado diariamente grandes quantidades de resíduos sólidos e efluentes, os quais se têm constituído em preocupação ambiental e econômica significativa (ALTESOR et al., 2008). Para cada 100 t de celulose produzida são gerados em torno de $48 \mathrm{t}$ de resíduos nas fábricas de papel e celulose (ARRUDA et al., 2011). A opção por aterro industrial para a deposição final desses resíduos é indesejável, em função do alto custo para sua implantação e manutenção, além da exigência de cuidados especiais no manuseio tendo em vista os riscos de contaminação ambiental (MAEDA; BOLOGNOLA, 2013).

Neste contexto, surgem oportunidades de estudos, no sentido de buscar soluções alternativas para a utilização desses resíduos em solos de áreas agrícolas nos plantios florestais permitindo seu aproveitamento e a diminuição do impacto ambiental. Entre os benefícios da aplicação de resíduos da extração de celulose em ecossistemas florestais podemos ressaltar a melhoria da fertilidade, correção do solo e aumento na produtividade de madeira (MACIEL et al., 2015).

Para avaliar as mudanças ocorridas no solo e o desenvolvimento do eucalipto é necessária a utilização da silvicultura de precisão associada à geoestatística. É realizada análise da dependência espacial de dados georreferenciados que são ajustados em semivariogramas em função das distâncias entre as observações. São elaborados mapas de krigagem para cada atributo pesquisado do solo e da planta que representará a variabilidade espacial dos dados e em seguida obtém-se as zonas específicas de manejo do solo para o atributo (CARVALHO et al., 2012).

Desta forma, o estudo da relação entre a capacidade produtiva de povoamentos de Eucalyptus spp. e dos atributos do solo favorece o manejo racional do sítio florestal evitando a degradação de seus atributos químicos e o baixo desenvolvimento das árvores. Tal estudo visa à produção sustentável, utilizando a geoestatística como importante instrumento na interpretação de resultados com base na estrutura da sua variabilidade espacial natural, principalmente na interação entre os atributos químicos do solo e o crescimento vegetal tornando-se viável intervenções localizadas na floresta, com exatidão e precisão adequadas (ROSA FILHO et al., 2011).

Diante do exposto, objetivou-se analisar as correlações lineares do desenvolvimento individual das árvores de Eucalyptus urograndis em função dos atributos químicos de um Neossolo Quartzarênico, com vistas a evidenciar zonas específicas de manejo intimamente associadas ao desenvolvimento do eucalipto no intuito de utilizar a lama de cal da extração da celulose na forma de fertilizantes de maneira sustentável ao ambiente.

\section{Material e Métodos}

O cultivo de Eucalyptus spp. no Brasil tem aumentado devido ao rápido crescimento, diversificação no uso da madeira e pela facilidade de adaptação às diferentes condições edafoclimáticas. Tal fato faz com que a produtividade das plantações comerciais de eucalipto no Brasil seja bastante variável. Segundo o Serviço Florestal Brasileiro (2016), o Brasil obtém hoje as melhores tecnologias na silvicultura do eucalipto, atingindo cerca de $60 \mathrm{~m}^{3} \mathrm{ha}^{-1}$ de produtividade média em rotações de sete anos.

O aumento na produção madeireira levou o setor de papel e celulose brasileiro a destaque na área florestal em âmbito mundial como o quarto maior produtor de celulose, o nono maior produtor de papel, além de ser o $13^{\circ}$ maior mercado de consumidores per capita de papel, contando com um total de 220 empresas de celulose e papel ativas em 540 municípios, localizados em 18 estados (TOLEDO et al., 2015).

Produzindo papel e celulose, as indústrias do setor florestal têm gerado diariamente grandes quantidades de resíduos sólidos e efluentes, os quais se têm constituído em preocupação ambiental e econômica significativa (ALTESOR et al., 2008). Para cada $100 \mathrm{t}$ de celulose produzida são gerados em torno de $48 \mathrm{t}$ de resíduos nas fábricas de papel e celulose (ARRUDA et al., 2011). A opção por aterro industrial para a deposição final desses resíduos é indesejável, em função do alto custo para sua implantação e manutenção, além da exigência de cuidados especiais no manuseio tendo em vista os riscos de contaminação ambiental (MAEDA; BOLOGNOLA, 2013).

Neste contexto, surgem oportunidades de estudos, no sentido de buscar soluções alternativas para a 
utilização desses resíduos em solos de áreas agrícolas nos plantios florestais permitindo seu aproveitamento e a diminuição do impacto ambiental. Entre os benefícios da aplicação de resíduos da extração de celulose em ecossistemas florestais podemos ressaltar a melhoria da fertilidade, correção do solo e aumento na produtividade de madeira (MACIEL et al., 2015).

Para avaliar as mudanças ocorridas no solo e o desenvolvimento do eucalipto é necessária a utilização da silvicultura de precisão associada à geoestatística. É realizada análise da dependência espacial de dados georreferenciados que são ajustados em semivariogramas em função das distâncias entre as observações. São elaborados mapas de krigagem para cada atributo pesquisado do solo e da planta que representará a variabilidade espacial dos dados e em seguida obtém-se as zonas específicas de manejo do solo para o atributo (CARVALHO et al., 2012).

Desta forma, o estudo da relação entre a capacidade produtiva de povoamentos de Eucalyptus spp. e dos atributos do solo favorece o manejo racional do sítio florestal evitando a degradação de seus atributos químicos e o baixo desenvolvimento das árvores. Visa também a produção sustentável, utilizando a geoestatística como importante instrumento na interpretação de resultados com base na estrutura da sua variabilidade espacial natural, principalmente na interação entre os atributos químicos do solo e o crescimento vegetal tornando-se viável intervenções localizadas na floresta, com exatidão e precisão adequadas (ROSA FILHO et al., 2011).

Diante do exposto, objetivou-se analisar as correlações lineares do desenvolvimento individual das árvores de Eucalyptus urograndis em função dos atributos químicos de um Neossolo Quartzarênico, com vistas a evidenciar zonas específicas de manejo intimamente associadas ao desenvolvimento do eucalipto no intuito de utilizar a lama de cal da extração da celulose na forma de fertilizantes de maneira sustentável ao ambiente.

No dia 25 de junho de 2014, a malha experimental recebeu $2 \mathrm{Mg} \mathrm{ha}^{-1}$ de corretivo do composto lama de cal + oxyfertil, $60 \%$ e $40 \%$ respectivamente. Na Tabela 2 estão discriminadas as porcentagens de óxido de cálcio e magnésio de cada produto.

O Oxyfertil ${ }^{\circledR} \quad 6030 \mathrm{~F}$ é um fertilizante mineral simples registrado no Ministério da Agricultura, Pecuária e Abastecimento - MAPA que em contato com água forma uma reação exotérmica formando hidróxidos de $\mathrm{Ca}(\mathrm{OH})_{2}$ e parcialmente de $\mathrm{Mg}(\mathrm{OH})_{2}$, liberando na ordem de $210 \mathrm{cal} \mathrm{g}^{-1}$ de calor. Possui solubilidade de aproximadamente $0,8 \mathrm{~g} \mathrm{~L}^{-1}\left(25^{\circ} \mathrm{C}\right)$ com pH (solução a $25{ }^{\circ} \mathrm{C}$ ) de 12,4 . Fisicamente o produto possui uma distribuição granulométrica (antes de reação com água) de 0-3 mm e distribuição granulométrica (após reação com água) de 0-0,2 mm.

Foram definidas as direções $x$ e $y$ do sistema de coordenadas cartesianas e de acordo com o espaçamento das plantas de eucalipto efetuou-se o estaqueamento global das malhas experimentais. A malha experimental foi constituída de cinco transeções, contendo 50 pontos amostrais (uma amostra simples por ponto em cada camada de solo) que seguiu o plantio de eucalipto em linhas, formando curva de nível para uma melhor conservação do solo. O espaçamento amostral foi de 7,5 x $3 \mathrm{~m}$.

Tabela 1. Análise inicial de alguns atributos químicos do solo estudado.

\begin{tabular}{|c|c|c|c|c|c|c|c|c|c|c|c|c|}
\hline \multirow{4}{*}{$\begin{array}{l}\text { Profundidade } \\
\text { (m) }\end{array}$} & \multicolumn{12}{|c|}{ Atributo químico $^{\text {(a) }}$} \\
\hline & \multirow{3}{*}{$\begin{array}{c}\mathrm{MO} \\
\mathrm{g} \mathrm{dm}^{-3}\end{array}$} & \multicolumn{11}{|c|}{ Complexo sortivo } \\
\hline & & $\mathrm{pH}$ & $P$ & $\mathrm{~K}^{+}$ & $\mathrm{Ca}^{2+}$ & $\mathrm{Mg}^{2+}$ & $\mathrm{H}^{+}+\mathrm{Al}^{3+}$ & $\mathrm{Al}^{3+}$ & SB & CTC & $\mathrm{V}$ & $\mathrm{m}$ \\
\hline & & $\mathrm{CaCl}_{2}$ & $\mathrm{mg} \mathrm{dm}^{-3}$ & ----- & $----\cdot$ & ----- & $---\mathrm{mmol}_{\mathrm{c}}$ & $m^{-3}--$ & ----- & ------- & & - \\
\hline $0-0,20$ & 12 & 4,1 & 8 & 0,9 & 1 & 2 & 36 & 8 & 3,9 & 39,9 & 10 & 67 \\
\hline $0,20-0,40$ & 14 & 4,1 & 4 & 0,9 & 2 & 0 & 26 & 12 & 2,9 & 20,9 & 10 & 81 \\
\hline
\end{tabular}

(a) $\mathrm{MO}, \mathrm{pH}, \mathrm{P}, \mathrm{K}^{+}, \mathrm{Ca}^{2+}, \mathrm{Mg}^{2+}, \mathrm{H}^{+}+\mathrm{Al}^{3+}, \mathrm{Al}^{3+}, \mathrm{SB}, \mathrm{CTC}, \mathrm{V}$ e $\mathrm{m}$ são respectivamente: matéria orgânica, potencial hidrogeniônico, fósforo, potássio, cálcio, magnésio, acidez potencial, alumínio, soma de bases, capacidade de troca catiônica, índice de saturação por bases e índice de saturação por alumínio.

Tabela 2. Características dos produtos utilizados.

\begin{tabular}{|c|c|c|c|}
\hline & $\mathrm{CaO}$ & $\mathrm{MgO}$ & PRNT \\
\hline & & $\%$ & -- \\
\hline Lama de Cal & 24 & 0,1 & - \\
\hline Oxyfertil & 60 & 30 & 175 \\
\hline
\end{tabular}


Os atributos do solo e da planta foram coletados no entorno de cada árvore representante do ponto amostral e ocorreram três meses após a aplicação da lama de cal + oxyfertyl e seis meses após o plantio do eucalipto. Os atributos de planta avaliados foram: altura das árvores (ALT), medida com o auxílio de uma régua graduada em metros; diâmetro altura do peito (DAP), medido a uma altura de $1,30 \mathrm{~m}$ do solo com o auxílio de um paquímetro digital. Os atributos do solo avaliados foram: fósforo $(\mathrm{P})$; matéria orgânica $(\mathrm{MO})$; valores de potencial hidrogeniônico $(\mathrm{pH})$; teores de potássio $\left(\mathrm{K}^{+}\right)$; cálcio $\left(\mathrm{Ca}^{2+}\right)$; magnésio $\left(\mathrm{Mg}^{2+}\right)$; alumínio $\left(\mathrm{Al}^{3+}\right)$; soma de bases (SB); e capacidade de troca catiônica (CTC), todos coletados nas camadas de 0,00-0,20 m e 0,20-0,40 m. A metodologia utilizada para determinar os atributos químicos seguiu as determinações de Raij et al. (2001).

O solo para a determinação da fertilidade foi coletado com auxílio de um trado de caneca e posteriormente foi obtida a terra fina seca ao ar (TFSA) passando as amostras de solo em peneira de malha de 2 $\mathrm{mm}$. A etapa laboratorial das análises químicas do solo foi efetuada no Laboratório de Fertilidade do Solo da Faculdade de Engenharia de Ilha Solteira - UNESP.

Para cada atributo estudado realizou-se análise descritiva estatística clássica. Utilizando o software SAS, calculou-se a média, mediana, moda, valores mínimo e máximo, desvio padrão, coeficiente de variação, curtose e assimetria. Também foi efetuada a análise da distribuição de frequência dos dados. Desta forma, para testar a hipótese de normalidade dos atributos, foi utilizado o teste de Shapiro e Wilk (1965) a $1 \%$. Foi montada a matriz de correlação entre todos os atributos pesquisados, contendo todas as combinações pareadas possíveis. Objetivou-se detectar a existência de correlações significativas entre os atributos da planta (variáveis dependentes) e os atributos do solo (variáveis independentes).

A análise geoestatística foi feita com o Gamma Design Software 7.0 (GS $\left.{ }^{+}, 2004\right)$, onde analisou a dependência espacial pelo cálculo do semivariograma, com bases nos pressupostos de estacionariedade da hipótese intrínseca. Foram ajustados semivariogramas simples a todos os atributos estudados da planta e do solo.

Os ajustes dos semivariogramas simples, em função de seus modelos, foram efetuados prioritariamente pela seleção inicial de: a) o maior coeficiente de determinação $\left(\mathrm{r}^{2}\right)$; b) a menor soma dos quadrados dos resíduos (SQR), e c) o maior avaliador do grau da dependência espacial (ADE). A decisão final do modelo que representou o ajuste foi realizada pela validação cruzada, assim como para a definição do tamanho da vizinhança que proporcionou a melhor malha de krigagem. Para cada atributo, foram estimados o efeito pepita $(\mathrm{Co})$, o alcance $(\mathrm{Ao})$ e o patamar $(\mathrm{Co}+\mathrm{C})$. Para a confecção dos mapas de krigagem utilizou-se o conjunto de softwares Gamma Design Software 7.0 $\left(\mathrm{GS}^{+}, 2004\right)$ e o Surfer 8.0 (Golden Software, 2002).

\section{Resultados e Discussão}

De acordo com a classificação do coeficiente de variação $(\mathrm{CV})$ proposta por Pimentel-Gomes e Garcia (2002), a variabilidade de um atributo pode ser classificada segundo a magnitude de seu coeficiente de variação. Sendo assim, no Tabela 3 está apresentada a análise descritiva dos atributos estudados. A altura (ALT) apresentou média variabilidade com coeficiente de variação de 18,23\%, corroborando com Rosa Filho et al. (2011) que encontraram valor mediano de $14,4 \%$ ao avaliar produtividade e atributos do solo em um sítio florestal de Eucalyptus urophylla.

A variabilidade da $\mathrm{MO} 2, \mathrm{pH} 2$ e CTC2 foram baixas, com CV entre 0,73 e 8,59\%. Para MO1, pH1 e CTC1 os valores de CV variaram entre $11,00 \%$ e 15,02\%. Já os atributos P1 e P2 apresentaram CV altos, de 22,98\% e 22,04\%, respectivamente. Para K1, K2, Ca1, Ca2, Mg1, $\mathrm{Mg} 2, \mathrm{~A} 11, \mathrm{Al} 2, \mathrm{SB} 1$ e SB2, os valores de CV foram muito altos, entre $33,59 \%$ e $93,28 \%$ (Tabela 3). Segundo Arthur et al. (2014), as variações dos atributos químicos do solo estão relacionadas à alterações provocadas por adubações e calagens irregulares e, devido à alta heterogeneidade em torno da média entre os atributos químicos na área avaliada. Essa heterogeneidade pode ter várias causas, dentre elas, o processo de formação do solo e acúmulo e distribuição das partículas do solo em função da forma do relevo e do fluxo de água na área.

$\mathrm{O}$ CV deve ser utilizado como parâmetro para validar os valores médios encontrados, uma vez que, segundo Pimentel-Gomes e Garcia (2002), coeficiente de variação maior que $30 \%$ revelam que a média tem pouco significado e valores maiores que $60 \%$ refletem série de dados muito heterogênea anulando a confiabilidade da média. Contudo, se for menor que $30 \%$, os dados são homogêneos e a média tem significado, podendo ser utilizada como representativa para os dados obtidos.

O DAP apresentou distribuição de frequência do tipo indeterminada, com coeficiente de assimetria de $-0,83$ e curtose foram de 0,20 , não sendo significativo a $5 \%$ de probabilidade pelo teste de normalidade uma vez que sua probabilidade foi de 0,0120. A ALT apresentou distribuição de frequência do tipo normal com coeficiente de assimetria de $-0,63$ e curtose de 0,03 . Contudo, a ALT foi significativa a $5 \%$ de probabilidade pelo teste de normalidade de Shapiro e Wilk (1965), uma vez que sua respectiva probabilidade foi de 0,0759 (Tabela 3). 
Tabela 3. Análise descritiva dos atributos de eucalipto e de um Neossolo Quartzarênico com aplicação de Lama de Cal + Oxyfertil.

\begin{tabular}{|c|c|c|c|c|c|c|c|c|c|c|}
\hline \multirow{3}{*}{ Atributos ${ }^{\text {(a) }}$} & \multicolumn{10}{|c|}{ Medidas estatísticas descritivas } \\
\hline & \multirow{2}{*}{ Média } & \multirow{2}{*}{ Mediana } & \multicolumn{2}{|c|}{ Valor } & \multirow{2}{*}{$\begin{array}{l}\text { Desvio } \\
\text { Padrão }\end{array}$} & \multicolumn{3}{|c|}{ Coeficiente } & \multicolumn{2}{|c|}{ Probabilidade } \\
\hline & & & Mínimo & Máximo & & Variação & Curtose & Assimetria & $\operatorname{Pr}<w$ & $\mathrm{DF}$ \\
\hline \multicolumn{11}{|c|}{ Atributos de planta } \\
\hline $\operatorname{ALT}(\mathrm{m})$ & 3,51 & 3,60 & 1,70 & 4,50 & 0,64 & 18,23 & 0,03 & $-0,63$ & 0,0759 & NO \\
\hline $\mathrm{DAP}(\mathrm{m})$ & 0,027 & 0,028 & 0,010 & 0,036 & 0,006 & 23,45 & 0,20 & $-0,83$ & 0,0120 & IN \\
\hline \multicolumn{11}{|c|}{ Atributos de solo } \\
\hline $\mathrm{P} 1\left(\mathrm{mg} \mathrm{dm}^{-3}\right)$ & 2,98 & 3,000 & 2,00 & 5,00 & 0,69 & 22,98 & 1,83 & 0,82 & 0,0001 & IN \\
\hline $\mathrm{P} 2\left(\mathrm{mg} \mathrm{dm}^{-3}\right)$ & 2,10 & 2,000 & 1,00 & 3,00 & 0,46 & 22,04 & 1,65 & 0,39 & 0,0001 & IN \\
\hline $\operatorname{MO} 1\left(\mathrm{mg} \mathrm{dm}^{-3}\right)$ & 11,52 & 11,00 & 11,00 & 15,00 & 1,29 & 11,13 & 1,09 & 0,98 & 0,0001 & IN \\
\hline $\mathrm{MO} 2\left(\mathrm{mg} \mathrm{dm}^{-3}\right)$ & 9,78 & 10,00 & 9,00 & 11,00 & 0,76 & 7,81 & $-1,16$ & 0,40 & 0,0001 & IN \\
\hline $\mathrm{pH} 1$ & 4,14 & 4,00 & 2,90 & 6,00 & 0,46 & 11,00 & 5,77 & 1,51 & 0,0001 & IN \\
\hline $\mathrm{pH} 2$ & 3,99 & 3,95 & 3,80 & 4,60 & 0,15 & 3,73 & 4,73 & 1,69 & 0,0001 & IN \\
\hline $\mathrm{K} 1\left(\mathrm{mmol}_{\mathrm{c}} \mathrm{dm}^{-3}\right)$ & 0,60 & 0,50 & 0,20 & 1,40 & 0,29 & 48,65 & 0,13 & 0,79 & 0,0049 & IN \\
\hline $\mathrm{K} 2\left(\mathrm{mmol}_{\mathrm{c}} \mathrm{dm}^{-3}\right)$ & 0,45 & 0,40 & 0,20 & 0,80 & 1,67 & 36,48 & $-0,17$ & 0,47 & 0,0001 & IN \\
\hline $\mathrm{Ca} 1\left(\mathrm{mmol}_{\mathrm{c}} \mathrm{dm}^{-3}\right)$ & 3,28 & 2,00 & 1,00 & 11,00 & 2,84 & 86,46 & 0,71 & 1,17 & 0,0001 & IN \\
\hline $\mathrm{Ca} 2\left(\mathrm{mmol}_{\mathrm{c}} \mathrm{dm}^{-3}\right)$ & 1,96 & 1,00 & 1,00 & 8,00 & 1,75 & 89,24 & 5,36 & 2,38 & 0,0001 & IN \\
\hline $\operatorname{Mg} 1\left(\mathrm{mmol}_{\mathrm{c}} \mathrm{dm}^{-3}\right)$ & 4,20 & 3,00 & 1,00 & 18,00 & 3,53 & 84,15 & 5,80 & 2,23 & 0,0001 & IN \\
\hline $\operatorname{Mg} 2\left(\mathrm{mmol}_{\mathrm{c}} \mathrm{dm}^{-3}\right)$ & 2,18 & 2,00 & 1,00 & 5,00 & 1,17 & 53,79 & $-0,37$ & 0,74 & 0,0001 & IN \\
\hline Al1 $\left(\mathrm{mmol}_{\mathrm{c}} \mathrm{dm}^{-3}\right)$ & 10,30 & 12,00 & 0,00 & 16,00 & 4,91 & 47,69 & $-0,57$ & $-0,73$ & 0,0004 & IN \\
\hline $\mathrm{Al} 2\left(\mathrm{mmol}_{\mathrm{c}} \mathrm{dm}^{-3}\right)$ & 12,46 & 14,00 & 0,00 & 16,00 & 4,19 & 33,59 & 1,74 & $-1,54$ & 0,0001 & IN \\
\hline $\mathrm{SB} 1\left(\mathrm{mmol}_{\mathrm{c}} \mathrm{dm}^{-3}\right)$ & 8,63 & 5,85 & 2,20 & 43,80 & 8,05 & 93,28 & 7,80 & 2,50 & 0,0001 & IN \\
\hline $\mathrm{SB} 2\left(\mathrm{mmol}_{\mathrm{c}} \mathrm{dm}^{-3}\right)$ & 4,42 & 3,45 & 2,20 & 12,80 & 2,50 & 56,49 & 3,01 & 1,70 & 0,0001 & IN \\
\hline $\mathrm{CTC} 1\left(\mathrm{mmol}_{\mathrm{c}} \mathrm{dm}^{-3}\right)$ & 35,51 & 35,45 & 27,20 & 52,80 & 5,33 & 15,02 & 2,26 & 1,04 & 0,0014 & IN \\
\hline CTC2 $\left(\mathrm{mmol}_{\mathrm{c}} \mathrm{dm}^{-3}\right)$ & 29,39 & 28,80 & 23,50 & 34,60 & 2,52 & 8,59 & $-0,33$ & 0,08 & 0,5471 & $\mathrm{NO}$ \\
\hline
\end{tabular}

(a) $\mathrm{ALT}=$ altura das árvores; DAP = diâmetro altura do peito; $\mathrm{P}, \mathrm{MO}, \mathrm{pH}, \mathrm{K}, \mathrm{Ca}, \mathrm{Mg}, \mathrm{Al}, \mathrm{SB}$ e CTC de 1 a 2 , são respectivamente fósforo, matéria orgânica, potencial hidrogeniônico, potássio, cálcio, magnésio, alumínio, soma de bases e capacidade de troca catiônica coletados nas camadas de 0,00-0,20m e 0,20-0,40m do solo; ${ }^{(b)} \mathrm{DF}=$ distribuição de frequência, sendo NO e IN respectivamente do tipo normal e indeterminada.

Entre os atributos de solo, apenas a CTC2 apresentou distribuição de frequência do tipo normal, portanto a respectiva medida de tendência central deverá ser representada pela média, com coeficientes de assimetria de 0,08 e curtose de 0,33 , sendo este atributo significativo a $5 \%$ de probabilidade pelo teste de normalidade de Shapiro e Wilk (1965), uma vez que a respectiva probabilidade foi de 0,5471. Os demais atributos do solo apresentaram distribuição de frequência do tipo indeterminada, portanto, as respectivas medidas de tendência central deverão ser representadas pelos valores da mediana. Os atributos apresentaram coeficientes de assimetria positivo entre 0,39 e 2,50, assim como negativo entre $-1,54$ e - $-0,44$. Os coeficientes de curtose positivo ficaram entre $0,13 \mathrm{e}$ 7,80 , assim como as negativos entre $-1,16$ e $-0,17$, sendo que todos estes coeficientes não foram significativos a $5 \%$ de probabilidade pelo teste de normalidade de Shapiro e Wilk (1965).

Os valores de assimetria positiva demonstraram haver tendência de concentração dos valores abaixo da média observada, sendo tal tendência tanto mais expressiva quanto maior for o valor obtido, situação inversa se dá para valores negativos desse coeficiente.
Com exceção do Al1 e Al2 que apresentaram distribuição de frequência platicúrtica, ou seja, curtose negativa, os demais parâmetros tiveram distribuição de frequência leptocúrtica, evidenciando que a maioria dos atributos do solo possui os dados próximos ao seu centro no gráfico de distribuição de frequência. Isso pode indicar que as medidas de tendência central não são dominadas por valores atípicos na distribuição.

Os valores médios encontrados para altura (ALT) e diâmetro altura do peito (DAP) foram de 3,51 m e 0,027 $\mathrm{m}$, respectivamente (Tabela 3). Prevedello et al. (2013) avaliando o crescimento inicial de Eucalyptus grandis em um Argissolo aos 12 meses de idade obtiveram altura de 3,58 m e DAP de 2,69 $\mathrm{cm}$, alturas estas inferiores ao presente estudo devido à maior idade do eucalipto. De acordo com os autores, o baixo desenvolvimento do eucalipto em altura ocorreu pois o solo manejado apresentou alta densidade e resistência mecânica à penetração do solo, fatores que não propiciaram crescimento radicular e aéreo da planta.

Por meio do estudo da correlação de Pearson (Tabela 4), foi possível observar correlações positivas e negativas entre os atributos do eucalipto e químicos do solo. 
Tabela 4. Matriz de correlação linear simples dos atributos de eucalipto e de um Neossolo Quartzarênico com aplicação de Lama de Cal + Oxyfertil.

\begin{tabular}{|c|c|c|c|c|c|c|c|c|c|c|c|c|c|c|c|c|c|c|c|}
\hline \multirow{2}{*}{ Atributos ${ }^{(a)}$} & \multicolumn{19}{|c|}{ Coeficiente de correlação $o^{(b)}$} \\
\hline & ALT & DAP & P1 & $\mathrm{P} 2$ & MO1 & $\mathrm{MO} 2$ & $\mathrm{pH} 1$ & $\mathrm{pH} 2$ & K1 & $\mathrm{K} 2$ & Ca1 & $\mathrm{Ca} 2$ & $\mathrm{Mg} 1$ & $\mathrm{Mg} 2$ & Al1 & $\mathrm{A} 12$ & SB1 & SB2 & CTC1 \\
\hline DAP & $0,624 * *$ & - & - & - & - & - & - & - & - & - & - & - & - & - & - & - & - & - & - \\
\hline $\mathrm{P} 1$ & 0,098 & 0,111 & - & - & - & - & - & - & - & - & - & - & - & - & - & - & - & - & - \\
\hline $\mathrm{P} 2$ & 0,003 & 0,077 & 0,199 & - & - & - & - & - & - & - & - & - & - & - & - & - & - & - & - \\
\hline MO1 & 0,007 & $-0,216$ & 0,152 & $-0,192$ & - & - & - & - & - & - & - & - & - & - & - & - & - & - & - \\
\hline $\mathrm{MO} 2$ & $-0,124$ & $-0,086$ & $-0,008$ & 0,063 & $0,307 *$ & - & - & - & - & - & - & - & - & - & - & - & - & - & - \\
\hline $\mathrm{pH} 1$ & $-0,060$ & 0,083 & $0,310^{*}$ & 0,049 & 0,263 & 0,142 & - & - & - & - & - & - & - & - & - & - & - & - & - \\
\hline $\mathrm{pH} 2$ & $-0,105$ & $-0,015$ & 0,018 & 0,281 & 0,188 & 0,160 & $0,258^{*}$ & - & - & - & - & - & - & - & & - & - & - & \\
\hline $\mathrm{K} 1$ & $-0,005$ & 0,026 & 0,174 & 0,139 & $0,483 * *$ & 0,183 & 0,216 & 0,216 & - & - & - & - & - & - & - & - & - & - & - \\
\hline $\mathrm{K} 2$ & $-0,052$ & 0,135 & 0,063 & $-0,098$ & $0,518 * *$ & $0,348^{*}$ & 0,146 & 0,146 & $0,650^{* *}$ & - & - & - & - & - & - & - & - & - & - \\
\hline $\mathrm{Ca} 1$ & $-0,123$ & $-0,142$ & 0,108 & 0,056 & $0,537 * *$ & $0,643 * *$ & $0,567 * *$ & $0,567 * *$ & $0,386^{* *}$ & $0,545^{* *}$ & - & - & - & - & - & - & - & - & - \\
\hline $\mathrm{Ca} 2$ & 0,003 & $-0,073$ & 0,135 & 0,257 & 0,091 & $0,402 * *$ & $0,516^{* *}$ & $0,516^{* *}$ & 0,100 & $0,296^{*}$ & $0,418 * *$ & - & - & - & - & - & - & - & - \\
\hline $\operatorname{Mg} 1$ & $-0,192$ & $-0,242$ & $0,313^{*}$ & 0,012 & $0,580 * *$ & $0,401 * *$ & $0,427 * *$ & $0,427 * *$ & $0,305^{*}$ & $0,305^{*}$ & $0,670 * *$ & $0,189 * *$ & - & - & - & - & - & - & - \\
\hline $\operatorname{Mg} 2$ & 0,064 & 0,101 & 0,207 & 0,267 & $0,357^{*}$ & $0,483 * *$ & $0,607 * *$ & $0,607 * *$ & $0,386^{* *}$ & $0,432 * *$ & $0,659 * *$ & $0,659 * *$ & $0,395^{* *}$ & - & - & - & - & - & - \\
\hline Al1 & 0,094 & 0,126 & $-0,283^{*}$ & $-0,121$ & $-0,414 * *$ & $-0,118$ & $-0,712 * *$ & $0,649 * *$ & $-0,295$ & $-0,406$ & $-0,836 * *$ & $-0,516^{* *}$ & $-0,803 * *$ & $-0,612 * *$ & - & - & - & - & - \\
\hline $\mathrm{A} 12$ & 0,044 & 0,136 & $-0,139$ & $-0,161$ & $-0,369 * *$ & $-0,338 * *$ & $-0,381 * *$ & $-0,556 * *$ & $-0,141$ & $-0,316^{*}$ & $-0,549 * *$ & $-0,772 * *$ & $-0,536 * *$ & $-0,686^{* *}$ & $0,704 * *$ & - & - & - & - \\
\hline SB1 & $-0,100$ & $-0,088$ & $0,348 *$ & 0,011 & $0,333^{*}$ & 0,013 & $0,432 *$ & $0,472 * *$ & $0,337 *$ & 0,256 & $0,706^{* *}$ & 0,264 & $0,818^{* *}$ & $0,454 * *$ & $-0,758$ & $-0,361 * *$ & - & - & - \\
\hline SB2 & 0,008 & $-0,019$ & 0,086 & 0,153 & $0,307^{*}$ & $0,429 * *$ & $0,522 * *$ & $0,654 * *$ & 0,239 & $0,367 * *$ & $0,648 * *$ & $0,824 * *$ & $0,358^{*}$ & $0,857 * *$ & $-0,679 * *$ & $-0,746^{* *}$ & $0,424 * *$ & - & - \\
\hline CTC1 & $-0,053$ & $-0,079$ & $0,367 *$ & 0,137 & $0,484 * *$ & 0,042 & 0,146 & $0,359 *$ & $0,401 * *$ & 0,202 & $0,506^{* *}$ & 0,037 & $0,674 * *$ & $0,358^{*}$ & $-0,454 * *$ & $-0,216$ & $0,756^{* *}$ & 0,204 & - \\
\hline CTC2 & $-0,005$ & $-0,040$ & 0,204 & 0,279 & 0,130 & $0,379 * *$ & 0,069 & $-0,010$ & 0,181 & 0,224 & 0,067 & 0,157 & 0,068 & $0,294 *$ & $-0,017$ & $-0,043$ & 0,003 & 0,137 & $0,291 *$ \\
\hline
\end{tabular}

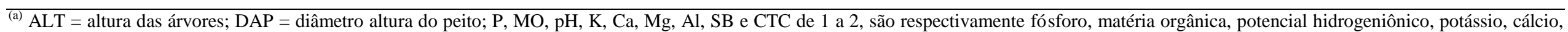
magnésio, alumínio, soma de bases e capacidade de troca catiônica coletados nas camadas de $0,00-0,20 \mathrm{~m}$ e $0,20-0,40 \mathrm{~m}$ do solo; ${ }^{(b)} *$ Significativo a $5 \%$, ** Significativo a $1 \%$. 
A correlação entre planta foi significativa apenas para o par ALT x DAP $(r=0,624 * *)$, demonstrando que, o DAP é dependente da altura, ou seja, com o crescimento em altura do eucalipto há um crescimento em DAP do eucalipto.

A análise de correlação inversa revelou que, dentre os maiores coeficientes encontrados, destacam-se aqueles que explicam a relação linear entre as medidas de acidez do solo para o Al1 x Ca1 $\left(r=-0,836^{* *}\right)$, Al1 x $\operatorname{Mg} 1\left(\mathrm{r}=-0,813^{* *}\right)$ e $\mathrm{Al} 2 \times \mathrm{Ca} 2\left(\mathrm{r}=-0,772^{* *}\right)$. Essa correlação inversa indica que com a diminuição dos teores de cálcio e magnésio, há um aumento substancial dos teores de alumínio no solo, ou seja, o alumínio no solo se torna muito mais solúvel tornando o solo tóxico para o desenvolvimento da planta; a toxidez por alumínio é um dos fatores mais formidáveis que restringem o desenvolvimento e a produção florestal em solos ácidos. A elevada concentração de $\mathrm{Al}$ são condições encontradas na maior parte dos solos tropicais, o que torna fundamental o conhecimento do comportamento de espécies florestais sob tais circunstâncias. Entretanto, segundo Silva et al. (2012) é importante ressaltar que, além destes teores não serem elevados, o eucalipto é mais tolerante ao alumínio trocável do que culturas anuais. Todavia, há a necessidade de repor cálcio e magnésio no solo extraído pelas plantas, objetivando evitar o esgotamento destes nutrientes no solo, o qual comprometeria negativamente a produtividade do eucalipto, sugerindo a necessidade da aplicação de calcário para a reposição desses nutrientes (CARDOSO et al., 2015).

As maiores correlações diretas foram Mg2 x SB2 (r $\left.=0,857^{* *}\right), \mathrm{Ca} 2 \times \mathrm{SB} 2\left(\mathrm{r}=0,824^{* *}\right)$ e $\mathrm{Mg} 1 \times \mathrm{SB} 1$ $\left(0,818^{* *}\right)$. Essa correlação direta indicou que com o aumento do teor de magnésio e cálcio no solo a partir da calagem, há uma maior soma de bases trocáveis (SB) do solo, fator que proporciona maior disponibilidade de nutrientes na solução do solo para as plantas. Dessa forma, com o aumento dos teores de cálcio e magnésio haverá um melhor desenvolvimento das plantas de eucalipto em altura e diâmetro. Este melhor desenvolvimento do eucalipto de acordo com Silva et al. (2012), ocorre devido à importância da disponibilização de cálcio no processo de sinalização celular, na determinação da permeabilidade da membrana, na composição da parede celular e no processo de divisão e desenvolvimento da célula. Da mesma forma, o magnésio é essencial para formar a clorofila, sintetizar proteínas, regular o $\mathrm{pH}$ celular e equilibrar cátions e ânions.

Na Tabela 5 estão apresentados os parâmetros dos semivariogramas simples para os atributos de planta e de solo. Os atributos que apresentaram dependência espacial foram o P1, Mo1, pH2, K1, K2, Ca1, Mg1, Mg2, Al1 e CTC2 (Tabela 5) Todos os demais atributos não apresentaram dependência espacial. A falta de dependência é um indicativo de que o valor de semivariância é igual ao patamar, para qualquer valor de distância. A ausência total de dependência espacial é chamada efeito pepita puro ("nugget effect"), ou seja, o alcance $\left(\mathrm{A}_{0}\right)$ dos dados é menor do que o menor espaçamento entre amostras coletadas. Para esses dados, tem-se uma distribuição espacial completamente aleatória e a única estatística aplicável é a estatística clássica (VIEIRA, 2000). O efeito pepita puro indica que a distribuição espacial do atributo na área de estudo é homogênea, aleatória ou a malha amostral utilizada não possui pontos suficientes para detectar a dependência que, se existir, será manifestada à distâncias menores que o menor espaçamento entre amostras (GUIMARÃES, 2004).

No presente estudo, a causa mais provável da homogeneidade espacial observada pode estar associada ao Neossolo Quartzarênico, em cuja classe não há variação da textura do solo e devido à idade prematura da cultura do eucalipto, com seis meses de idade.

Em relação ao desempenho dos semivariogramas, o maior coeficiente de determinação espacial $\left(r^{2}\right)$ observado para o ajuste do modelo foi 0,806 na modelagem da dependência espacial para a MO1 e o menor coeficiente foi 0,107 na modelagem da dependência espacial do $\mathrm{pH} 2$ (Tabela 5). Todos os modelos foram selecionados após análise de validação cruzada. O modelo teórico que apresentou melhor ajuste para a semivariância empírica dos atributos químicos do solo foi o esférico e o exponencial. De acordo com Bottega et al. (2013), quando os semivariogramas são apresentados como esférico e exponencial apresentam simultaneamente, baixa e média continuidade da variabilidade espacial, no entanto, o modelo gaussiano constitui-se de um elevado prosseguimento da variabilidade espacial. Estes ajustes podem ser explicados pelas alterações físico-químicas realizadas no solo, principalmente pelos atributos químicos que se modificam em função das práticas de correção e fertilização. Assim, a MO1 foi o atributo de melhor ajuste semivariográfico com um avaliador de dependência espacial (ADE) de 73,8\% apresentando uma alta dependência espacial.

A relação decrescente dos alcances $(\mathrm{m})$ foi a seguinte: P2 (28,2), K2 (25,5), K1 $(23,4), \mathrm{MO} 1(17,4)$, Ca1 $(16,8), \operatorname{Mg} 1(15,6), \mathrm{pH} 2(14,4)$, Al1 $(11,7)$, CTC1 $(11,7)$ e $\mathrm{Mg} 2(11,4)$.

Portanto, nas condições da presente pesquisa, os valores dos alcances a serem utilizados nos pacotes geoestatísticos que alimentarão os pacotes computacionais empregados na silvicultura de precisão, de forma geral, não deverão ser menores do que $11,4 \mathrm{~m}$ quando utilizado o corretivo lama de cal + oxyfertil. 
Tabela 5. Parâmetros dos semivariogramas simples e validações cruzadas ajustadas para os atributos do eucalipto e de um Neossolo Quartzarênico com aplicação de Lama de Cal + Oxyfertil.

\begin{tabular}{|c|c|c|c|c|c|c|c|c|c|c|c|}
\hline \multirow{3}{*}{ Atributos ${ }^{\text {(a) }}$} & \multicolumn{11}{|c|}{ Parâmetros } \\
\hline & \multirow{2}{*}{ Modelo $^{(\mathrm{b})}$} & \multirow{2}{*}{$\begin{array}{c}\text { Efeito pepita } \\
\qquad\left(\mathrm{C}_{0}\right)\end{array}$} & \multirow{2}{*}{$\begin{array}{l}\text { Patamar } \\
\left(\mathrm{C}_{0}+\mathrm{C}\right)\end{array}$} & \multirow{2}{*}{$\begin{array}{l}\text { Alcance } \\
\left(\mathrm{A}_{0}\right)(\mathrm{m})\end{array}$} & \multirow{2}{*}{$r^{2}$} & \multirow{2}{*}{$\mathrm{SQR}^{(\mathrm{c})}$} & \multicolumn{2}{|c|}{$\mathrm{ADE}^{(\mathrm{d})}$} & \multicolumn{3}{|c|}{ Validação cruzada } \\
\hline & & & & & & & $\%$ & Classe & $\mathrm{a}$ & $\mathrm{b}$ & $\mathrm{r}$ \\
\hline $\operatorname{ALT}(\mathrm{m})$ & epp & 0,335 & 0,335 & - & - & - & - & - & - & - & - \\
\hline $\mathrm{DAP}(\mathrm{m})$ & epp & $5.10^{-4}$ & $5.10^{-4}$ & - & - & - & - & - & - & - & - \\
\hline $\mathrm{P} 1\left(\mathrm{mg} \mathrm{dm}{ }^{-3}\right)$ & epp & $4,670.10^{-1}$ & $4,670.10^{-1}$ & - & - & - & - & - & - & - & - \\
\hline $\mathrm{P} 2\left(\mathrm{mg} \mathrm{dm}^{-3}\right)$ & $\exp (30)$ & $3,100.10^{-2}$ & $1,670.10^{-1}$ & 28,2 & 0,538 & $4,975 \cdot 10^{-3}$ & 81,4 & MA & 1,41 & 0,319 & 0,109 \\
\hline $\operatorname{MO1}\left(\mathrm{mg} \mathrm{dm}^{-3}\right)$ & esf (46) & $3,580.10^{-1}$ & 1,368 & 17,4 & 0,806 & $5,600 \cdot 10^{-2}$ & 73,8 & $\mathrm{AL}$ & 2,60 & 0,776 & 0,336 \\
\hline $\operatorname{MO} 2\left(\mathrm{mg} \mathrm{dm}^{-3}\right)$ & epp & $5,980.10^{-1}$ & $5,980 \cdot 10^{-1}$ & - & - & - & - & - & - & - & - \\
\hline pH1 & epp & $2,200.10^{-1}$ & $2,200.10^{-1}$ & - & - & - & - & - & - & - & - \\
\hline $\mathrm{pH} 2$ & $\exp (89)$ & $6,100.10^{-3}$ & $2,400 \cdot 10^{-2}$ & 14,4 & 0,107 & $9,900 \cdot 10^{-5}$ & 74,6 & $\mathrm{AL}$ & 4,97 & $-0,247$ & 0,077 \\
\hline $\mathrm{K} 1\left(\mathrm{mmol}_{\mathrm{c}} \mathrm{dm}^{-3}\right)$ & $\exp (84)$ & $1,500.10^{-2}$ & $9,150.10^{-2}$ & 23,4 & 0,764 & $2,500.10^{-4}$ & 83,2 & MA & 0,29 & 0,534 & 0,232 \\
\hline $\mathrm{K} 2\left(\mathrm{mmol}_{\mathrm{c}} \mathrm{dm}^{-3}\right)$ & $\exp (49)$ & $3,700.10^{-3}$ & $2,416.10^{-2}$ & 25,5 & 0,577 & $7,400.10^{-5}$ & 84,6 & MA & $-0,08$ & 0,307 & 0,545 \\
\hline $\mathrm{Ca} 1\left(\mathrm{mmol}_{\mathrm{c}} \mathrm{dm}^{-3}\right)$ & $\exp (51)$ & $8,200.10^{-1}$ & 5,951 & 16,8 & 0,419 & 3,710 & 86,2 & MA & 2,07 & 0,307 & 0,114 \\
\hline $\mathrm{Ca} 2\left(\mathrm{mmol}_{\mathrm{c}} \mathrm{dm}^{-3}\right)$ & epp & 2,463 & 2,463 & - & - & - & - & - & - & - & - \\
\hline $\operatorname{Mg} 1\left(\mathrm{mmol}_{\mathrm{c}} \mathrm{dm}^{-3}\right)$ & $\exp (89)$ & 2,640 & $1,328.10$ & 15,6 & 0,156 & $3,330.10$ & 80,1 & MA & 3,81 & 0,094 & 0,032 \\
\hline $\operatorname{Mg} 2\left(\mathrm{mmol}_{\mathrm{c}} \mathrm{dm}^{-3}\right)$ & $\exp (67)$ & $2,080.10^{-1}$ & 1,43 & 11,4 & 0,380 & $6,980.10^{-2}$ & 85,4 & MA & 2,40 & $-0,176$ & 0,001 \\
\hline $\operatorname{Al}\left(\mathrm{mmol}_{\mathrm{c}} \mathrm{dm}^{-3}\right)$ & $\exp (64)$ & 2,46 & $2,236.10$ & 11,7 & 0,572 & 9,91 & 89,0 & MA & 17,97 & $-0,722$ & 0,195 \\
\hline Al2 $\left(\mathrm{mmol}_{\mathrm{c}} \mathrm{dm}^{-3}\right)$ & epp & $1,807.10$ & $1,807.10$ & - & - & - & - & - & - & - & - \\
\hline $\mathrm{SB} 1\left(\mathrm{mmol}_{\mathrm{c}} \mathrm{dm}^{-3}\right)$ & epp & $6,172.10$ & $6,172.10$ & - & - & - & - & - & - & - & - \\
\hline $\mathrm{SB} 2\left(\mathrm{mmol}_{\mathrm{c}} \mathrm{dm}^{-3}\right)$ & epp & 6,436 & 6,436 & - & - & - & - & - & - & - & - \\
\hline $\mathrm{CTC} 1\left(\mathrm{mmol}_{\mathrm{c}} \mathrm{dm}^{-3}\right)$ & $\exp (66)$ & 2,79 & $1,863.10$ & 11,7 & 0,339 & $1,490.10$ & 85,0 & MA & $-5,43$ & 1,156 & 0,375 \\
\hline CTC2 $\left(\mathrm{mmol}_{\mathrm{c}} \mathrm{dm}^{-3}\right)$ & epp & 6,20 & 6,20 & - & - & - & - & - & - & - & - \\
\hline
\end{tabular}

(a) $\mathrm{ALT}$ = altura das árvores; DAP = diâmetro altura do peito; $\mathrm{P}, \mathrm{MO}, \mathrm{pH}, \mathrm{K}, \mathrm{Ca}, \mathrm{Mg}, \mathrm{Al}, \mathrm{SB}$ e CTC de 1 a 2, são respectivamente matéria orgânica, potencial hidrogeniônico, potássio, cálcio, magnésio, alumínio, soma de bases e capacidade de troca catiônica coletados nas camadas de $0,00-0,20 \mathrm{~m}$ e 020-0,40m do solo; ${ }^{(b)}$ epp = efeito pepita puro; exp = exponencial; esf = esférico; ${ }^{(c)} \mathrm{SQR}=$ soma dos quadrados dos resíduos, ${ }^{\text {(d) }}$ ADE = avaliador da dependência espacial sendo muito alta dependência espacial (MA); alta dependência (AL); $a=$ intercepto do eixo; $b=$ coeficiente angular; $r=$ coeficiente de correlação.

Analisando os atributos químicos do solo, o menor valor para o coeficiente de correlação encontrado foi de 0,001 para o $\mathrm{Mg} 2$ e o maior valor de 0,546 foi observado para K2. Os baixos coeficientes de correlação são decorrentes da dispersão da nuvem de pontos em torno da reta ideal, que possui coeficiente angular de valor 1 e corta a origem do eixo y (intercepto) no valor zero.

Dessa forma, do ponto de vista da análise geoestatística, o K2 foi o atributo que se apresentou como plausível indicador da qualidade química do solo quando esteve sob aplicação de lama de cal + oxyfertil para correção do solo com coeficiente angular (b) da validação cruzada de 0,307 .

Em relação aos mapas de krigagem (Figura 1), podese observar um arranjo de distribuição espacial dos atributos químicos bem definidos na área avaliada, o que permitiu identificar zonas homogêneas e específicas do solo, bem distintas para a maioria dos atributos estudados. Constatou-se que, os mapas com elevada semelhança espacial para efeito prático de manejo do solo foram os de MO1 (Figura 1B), K1 (Figura 1D), Ca1 (Figura 1F) e Mg1 (Figura 1G). As referidas semelhanças entre tais mapas de krigagem ocorreram na região leste onde se concentram os maiores teores de matéria orgânica $\left(12,2-14,2 \mathrm{mg} \mathrm{dm}^{-3}\right)$ na camada de 0,00-0,020. Visto que a matéria orgânica é o principal condicionador de nutrientes do solo, principalmente nos arenosos, consequentemente observou-se também os maiores teores de potássio $\left(0,65-1,05 \mathrm{mmol}_{\mathrm{c}} \mathrm{dm}^{-3}\right)$, cálcio $\left(4,6-8,2 \mathrm{mmol}_{\mathrm{c}} \mathrm{dm}^{-3}\right)$ e magnésio $(4,0-13,0$ $\left.\mathrm{mmol}_{\mathrm{c}} \mathrm{dm}^{-3}\right)$.

Os mapas de isolinhas obtidos por meio da interpolação dos dados, - método da krigagem, são fundamentais na silvicultura de precisão. Tais dados são posteriormente analisados e trabalhados com a finalidade de se planejar novas amostragens e realizar adubações e correções de solo mais exatas, com menor relação custo/benefício, de acordo com a variabilidade espacial dos valores de cada atributo avaliado. 

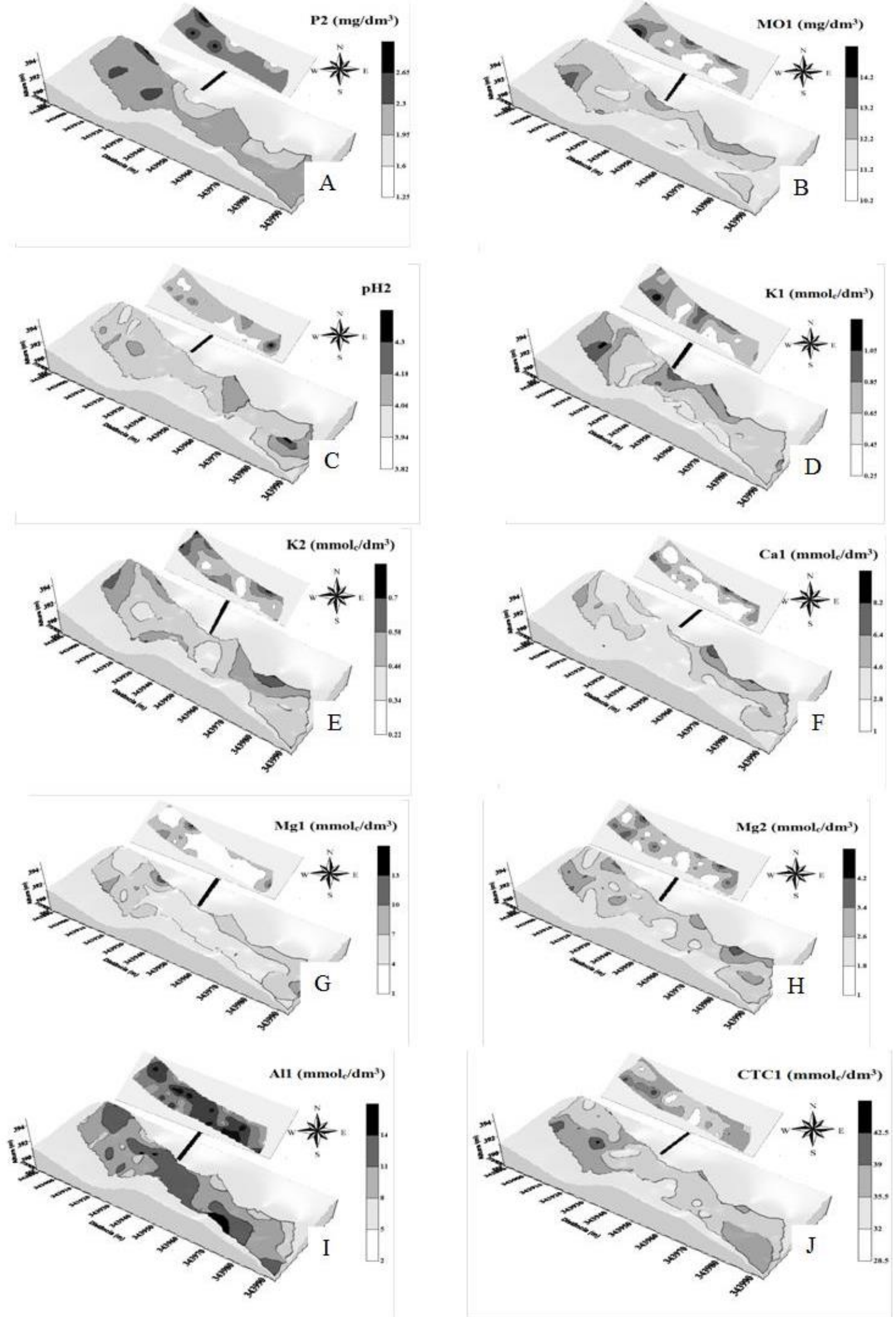

Figura 1. Mapas de krigagem dos atributos $\mathrm{P} 2, \mathrm{MO} 1, \mathrm{pH} 2, \mathrm{~K} 1, \mathrm{~K} 2, \mathrm{Ca} 1, \mathrm{Mg} 1, \mathrm{Mg} 2$, Al1 e CTC2. 


\section{Conclusões}

As propriedades dendrométricas do eucalipto mostraram média variabilidade, enquanto para os atributos do solo foram baixa, alta e muito alta.

A aplicação do composto lama de cal + oxyfertil na forma de fertilizantes, de maneira sustentável ao ambiente, promoveu melhoria nos teores de cálcio e magnésio no solo, sendo este recomendável na substituição do calcário.

Espacialmente, as propriedades dendrométricas do eucalipto apresentaram efeito pepita puro e a grande maioria dos atributos do solo apresentou dependência espacial, que variou conforme o atributo químico avaliado e a profundidade de coleta. Além da variabilidade vertical, há também variabilidade horizontal entre as profundidades, visto que para um mesmo nutriente o alcance foi diferente entre as camadas amostradas.

\section{Agradecimentos}

À FAPESP, processo número: 2013/25329-5 e ao incentivo à captação de recursos - FUNDUNESP processo número: 2333/002/14-PROPe/CDC pelo apoio financeiro e à Eldorado Brasil Celulose de Três Lagoas, MS por ter concedido a área.

\section{Referências Bibliográficas}

ALTESOR, A.; EGUREN, G.; MAZZEO, N.; PANARIO, D.;RODRIGUEZ, C. La indústria de la celulosa y sus efectos: certezas e incertidumbres. Ecologia Austral, Córdoba, v. 18, n. 3, p. 291-303, 2008 .

ARRUDA, O. G.; TARSITANO, M. A. A.; ALVES, M. C.; GIÁCOMO, R. G. Comparação de custos de implantação de eucalipto com resíduo celulósico em substituição ao fertilizante mineral. Revista Ceres, Viçosa-MG, v. 58, n. 5, p. 576-583, 2011

ARTUR, A. G.; OLIVEIRA, D. P.; COSTA, M. C. G.; ROMERO, R. E.; SILVA, M. V. C.; FERREIRA, T. O. Variabilidade espacial dos atributos químicos do solo, associada ao microrrelevo. Revista Brasileira de Engenharia Agrícola e Ambiental, Campina Grande-PB, v. 18, n. 2, p. 141-149, 2014.

BOTTEGA, E. L.; QUEIROZ, D. M.; PINTO, F. A. C.; SOUZA, C. M. A. Variabilidade espacial de atributos do solo em sistema de semeadura direta com rotação de culturas no cerrado brasileiro. Revista Ciência Agronômica, FortalezaCE v. 44, n. 1, p. 1-9, 2013.

CARDOSO, A. A. S.; SANTOS, J. Z. L.; TUCCI, C. A. F.; FARIAS, E. P.; MOURA, R. P. M. Influência da acidez e do teor de fósforo do solo no crescimento inicial do mogno. Pesquisa Florestal Brasileira, Colombo-PR, v. 35, n. 81, p. 1-10, 2015.
CARVALHO, M. P.; MENDONCA, V. Z. ; PEREIRA, F. C. B. L.; ARF, M. V.; KAPPES, C.; DALCHIAVON, F. C. Produtividade de madeira do eucalipto correlacionada com atributos do solo visando ao mapeamento de zonas específicas de manejo. Ciência Rural, Santa Maria-RS, v. 42, n. 10, p. 1797-1803, 2012.

EMBRAPA. EMPRESA BRASILEIRA DE PESQUISA AGROPECUÁRIA Sistema Brasileiro de Classificação de Solos. $3^{\text {a }}$ ed. Brasília-DF: Embrapa, 2013, 353p.

Golden Software. Surfer for Windows version 8.0. Colorado: Golden, 2002. 1 CD-ROM.

$\mathrm{GS}^{+}$. Geostatistics for environmental sciences. Plainwell: Gamma Design Software, 2004, 159p.

GUIMARÃES, E. C. Geoestatística básica e aplicada. Uberlândia-MG: Universidade Federal de Uberlândia, 2004. $76 \mathrm{p}$.

KÖPPEN, W. Climatologia: con un estudio de los climas de la tierra. México: Fondo de Cultura Económica, 1948. 478p.

MACIEL, T. M. S.; ALVES, M. C.; SILVA, F. C. Atributos químicos da solução e do solo após aplicação de resíduo da extração de celulose. Revista Brasileira de Engenharia Agrícola e Ambiental, Campina Grande-PE, v. 19, n. 1, p. 84-90, 2015

MAEDA, S.; BOGNOLA, I. A. Propriedades químicas de solo tratado com resíduos da indústria de celulose e papel. Pesquisa Florestal Brasileira, Colombo-PR v. 33, n.74, p. 168-177, 2013.

PIMENTEL-GOMES, F.; GARCIA, C. H. Estatística aplicada a experimentos agronômicos e florestais: Exposição com exemplos e orientações para uso de aplicativos. Piracicaba-SP: Fundação Escola de Agricultura Luiz de Queiroz.- Fealq, 2002. 309p.

PREVEDELLO, J.; KAISER, D. R.; REINERT, D. J.; VOGELMANN, E. S.; FONTANELA, E.; JOSÉ REICHERT, M. Manejo do solo e crescimento inicial de Eucalyptus grandis Hill ex Maiden em argissolo. Ciência Florestal, Santa Maria-RS, v. 23, n. 1, p. 129-138, 2013.

RAIJ, B. V.; ANDRADE, J. C.; CANTARELLA, H.; QUAGGIO, J. A. Análise química para avaliação da fertilidade de solos tropicais. Campinas-SP: Instituto Agronômico, 2001. 285p.

ROSA FILHO, G.; CARVALHO, M. P.; MONTANARI, R.; SILVA, J. M.: SIQUEIRA, G. M.; ZAMBIANCO, E. C. Variabilidade espacial de propriedades dendrométricas do eucalipto e de atributos físicos de um Latossolo Vermelho. Bragantia, Campinas-SP, v. 70, n. 2, p. 439-446, 2011.

SFB. SERVIÇO FLORESTAL BRASILEIRO As florestas plantadas. Brasília-DF: SFB, 2016. Disponível em: <http://www.florestal.gov.br/snif/recursos-florestais/estoquedas-florestas $>$. Acesso em: 12 mai. 2016.

SHAPIRO, S. S.; WILK, M. B. An analysis of variance test for normality: complete samples. Biometrika, London, v. 52, n. 3/4, p. 591-611, 1965. 
SILVA, M. D. O. P.; CORREA, G. F.; COELHO, L.; RABELO, P. G. Avaliação de dois tratamentos de adubação em plantio de eucalipto clonal em solo arenoso. Bioscience Journal, Uberlândia-MG, v. 28, n. 1, p. 212-222, 2012.

TOLEDO, F. H. S. F.; VENTURIN, N.; CARLOS, L.; DIAS, B. A. S.; VENTURIN, R. P.; MACEDO, R. L. G. Composto de resíduos da fabricação de papel e celulose na produção de mudas de eucalipto. Revista Brasileira de Engenharia Agrícola e Ambiental, Campina Grande-PE, v. 19, n. 7, p. 711-716, 2015.

VIEIRA, S. R. Geoestatística em estudos de variabilidade especial do solo. In: NOVAIS, R. F.; ALVAREZ, V. H., SCHAEFER, C. E. G. R. (ed.). Tópicos em ciência do solo. Viçosa-MG: SBCS, 2000. v. 1, p.1-53. 